Electronic Supplementary Information

\title{
Unprecedented Self-Assembly in Dilute Aqueous Solution of Polyethyleneimine: Formation of Fibrillar Network
}

Mehak Jain, ${ }^{a}$ Jyoti R. Seth ${ }^{b}$ Lohitha R. Hegde, ${ }^{a}$ and Kamendra P. Sharma $* a$

${ }^{a}$ Department of Chemistry, and ${ }^{\mathrm{b}}$ Department of Chemical Engineering, Indian Institute of Technology Bombay, Powai-400076, Mumbai, INDIA

\section{Table of Contents:}

\section{Experimental}

(i) Characterization

(a) Protonation fraction Calculations

\section{Supplementary Figures}




\section{Experimental:}

\section{(i) Characterization}

\section{Protonation fraction calculations:}

Protonation fraction here refers to the percentage of amine groups protonated in one PEI chain for a $750 \mathrm{kDa}$ PEI branched polymer. For the titration measurements $50 \mu \mathrm{M}(50 \mathrm{~mL}) 750 \mathrm{kDa}$ PEI aqueous solution was prepared at room temperature. $6 \mathrm{~N} \mathrm{HCl}$ was utilized for carrying out titrations. The native $\mathrm{pH}$ of PEI was 10.65 before addition of $\mathrm{HCl}$. Fixed aliquots of $\mathrm{HCl}(200 \mu \mathrm{L})$ were added to PEI solution with continuous stirring and change in $\mathrm{pH}$ was recorded after 5 minutes of every additions. The $\mathrm{pH}$ was brought to 1 and no volume was removed during the entire experiment. Three set of readings were taken for consistency.

Protonation fraction was calculated as:

Protonation $(P)=\frac{\text { Number of } H^{+} \text {ions absorbed by } 1 \text { PEI } \text { chain }(b)}{\text { Number of amine groups }(a)} \ldots \ldots \ldots$ (Eq.1)

Number of amine groups on one chain were calculated by dividing molecular weight 750,000 of PEI by average molecular weight of monomer, i.e $43\left(-\mathrm{CH}_{2}-\mathrm{CH}_{2}-\mathrm{NH}_{2}-\right)$. As each monomer has one amine group, the no. of monomers was equivalent to no. of amine groups on one PEI chain.

(a) Number of amine groups $=\frac{\text { Molecular weight of PEI }}{\text { Avg. molecular weight of } \text { monomer }}=\frac{750,000}{43}=17441$

Number of $\mathrm{H}^{+}$ions absorbed by 1 PEI chain was estimated as ratio between moles of $\mathrm{H}^{+}$absorbed by moles of PEI in solution and total number of moles of PEI in solution.

(b) Number of $\mathrm{H}^{+}$ions absorbed by 1 PEI chain $=\frac{\text { moles of } \mathrm{H}^{+} \text {absorbed by moles of PEI }(d)}{\text { moles of PEI in solution }(c)}$ (Eq.2)

(c) Moles of PEI in solution was calculated as: $C_{t} \times V_{t} \times 10^{-6} \ldots \ldots \ldots$ (Eq.3) 
where, $C_{t}$ is the concentration at time ' $\mathrm{t}$ ' and can be evaluated from starting concentration $(C)$, starting volume $(\mathrm{V})$ of PEI as:

$$
C_{t}=\frac{C \times V}{V_{t}} \ldots \ldots \ldots \ldots(\text { Eq.4) }
$$

and $\mathrm{V}_{\mathrm{t}}$ is the final volume at time ' $\mathrm{t}$ ' equivalent to initial volume $\mathrm{V}+$ volume of $\mathrm{HCl}$ added $\left(\mathrm{V}_{\mathrm{i}}\right)$.

For, pH $3 \mathrm{~V}_{\mathrm{i}}$ was $5.2 \mathrm{~mL}$ which gave $\mathrm{V}_{\mathrm{t}} 55.2 \mathrm{~mL}$. $C_{t}$ calculated for PEI solution at $\mathrm{pH} 3$ was $45.28 \mu \mathrm{M}$. While for $\mathrm{pH} 1 \mathrm{~V}_{\mathrm{i}}$ was $6.6 \mathrm{~mL}$ which gave $\mathrm{V}_{\mathrm{t}} 56.6 \mathrm{~mL}, C_{t}$ calculated for PEI solution at $\mathrm{pH} 1$ was $41.16 \mu \mathrm{M}$. Substituting the values of $C_{t}$ in equation 3, moles of PEI in solution at $\mathrm{pH} 3$ were $45.3 \mu$ moles and at $\mathrm{pH} 1$ were $44.1 \mu$ moles.

(d) Moles of $\mathrm{H}^{+}$absorbed by moles of PEI in solution was given by:

(Moles of $\mathrm{H}^{+}$present in native PEI solution $)+\left(\right.$Moles of $\mathrm{H}^{+}$added in solution - Moles of $\mathrm{H}^{+}$ remaining in solution)

$$
\left(V \times 1000 \times 10^{-10.65}\right)+\left(\text { starting concn. of } \mathrm{HCl}(6 N) \times V_{i}\right)-\left(V_{t} \times 1000 \times 10^{-x}\right)
$$

where $x$ is the value of $\mathrm{pH}$ at time $\mathrm{t}$.

At $\mathrm{pH} 3$ after substituting the values of $\mathrm{V}_{\mathrm{i}}=5.2 \mathrm{~mL}, \mathrm{~V}_{\mathrm{t}}=55.2 \mathrm{~mL}, \mathrm{~V}=50 \mathrm{~mL}$ and $x=3$ we get $31175.9 \mu$ moles of $\mathrm{H}^{+}$absorbed by PEI in solution.

At $\mathrm{pH} 1$ after substituting the values of $\mathrm{V}_{\mathrm{i}}=6.6 \mathrm{~mL}, \mathrm{~V}_{\mathrm{t}}=56.6 \mathrm{~mL}, \mathrm{~V}=50 \mathrm{~mL}$ and $x=1$ we get $34068.8 \mu$ moles of $\mathrm{H}^{+}$absorbed by PEI in solution.

After substituting the values for (c) and (d) in equation 2 number of $\mathrm{H}^{+}$ions per PEI chain were

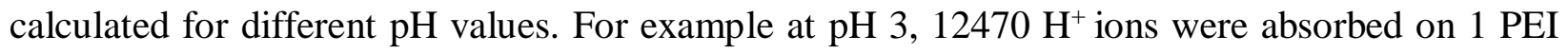
chain and for $\mathrm{pH} 1,13627 \mathrm{H}^{+}$ions were absorbed on 1 PEI chain at room temperature.

Finally the protonation fraction was calculated using equation 1 and inserting the values of (a) at different $\mathrm{pH}$ values and (b) as 17441 . For $\mathrm{pH} 3$ the protonation fraction was calculated as $71.5 \%$, while for $\mathrm{pH} 1$ the protonation was $79.1 \%$. 


\section{Small Angle X-Ray Scattering:}

The size of PEI chains/aggregates was obtained by applying Guinier approximation (as shown below) on the treated data:

$$
I(q)=\exp \exp \left(\frac{-R_{g} q^{2}}{3}\right)
$$

Using the above equation the radius of gyration was calculated, as a slope of plot between square of scattering vector $\left(q^{2}\right)$ and $\log$ of Intensity $(I)$, such that Radius of Gyration i.e. $R_{\mathrm{g}}$ is:

$$
\text { Slope }=\frac{-R_{g}{ }^{2}}{3}
$$

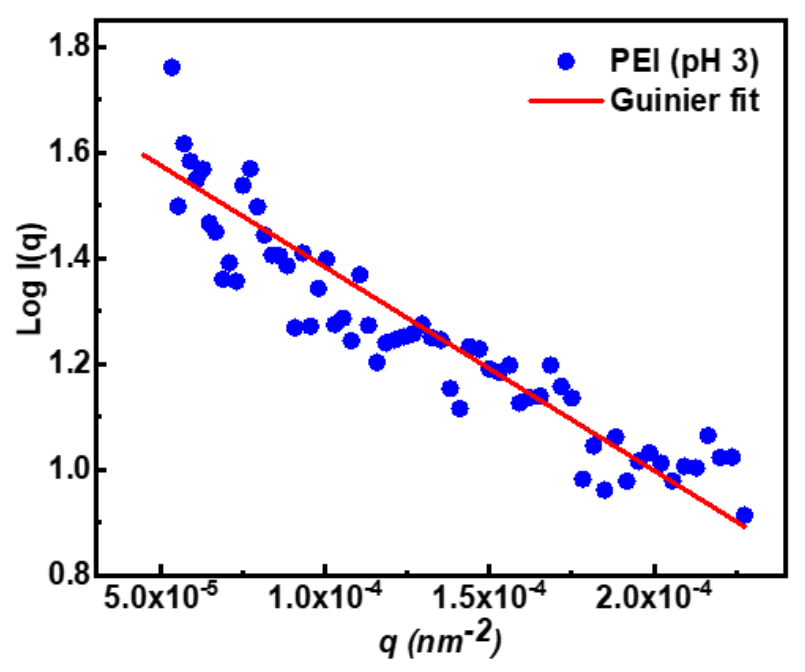

The slope was calculated as -3945.22 , inserting value of slope in Eq. $2 R_{\mathrm{g}}$ was calculated as 108.7 $\mathrm{nm}$. This suggested the PEI existed as multi-chain aggregates and not as single chains. The $R_{\mathrm{g}}$ for PEI aggregates was in agreement to size $~ 200 \mathrm{~nm}$ of PEI particles found in cryo SEM data for freshly prepared samples at pH 3 and the hydrodynamic radius $\left(d_{\mathrm{h}}\right)$ for similar PEI sample as 162 nm. 


\section{Figures:}

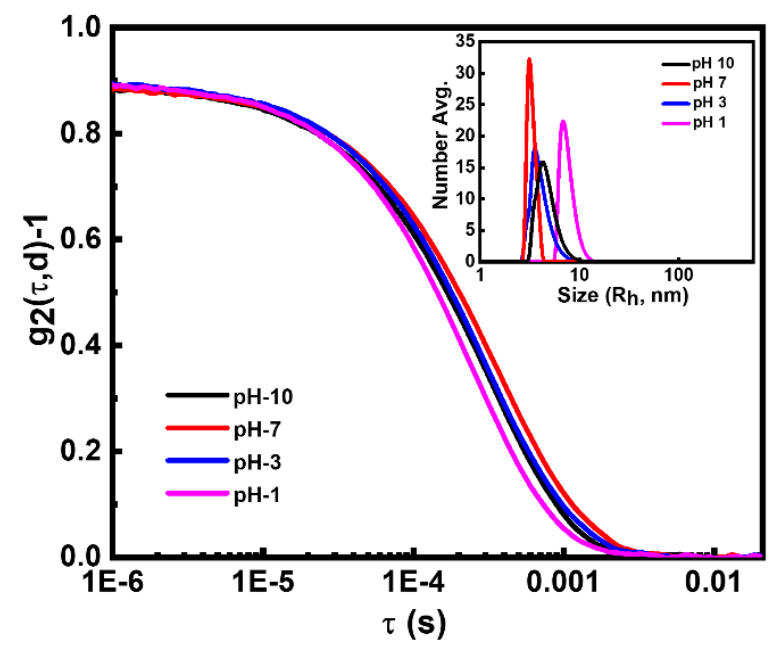

Figure S1a: Dynamic Light Scattering (DLS) plot of decay for autocorrelation function $\left(\mathrm{g}_{2}(\tau, \mathrm{d})\right.$ 1) with respect to $\tau(\mathrm{s})$ and inset showing "number" average distribution vs size (log scale) in solution for PEI $\mathrm{M}_{\mathrm{w}} 750 \mathrm{kDa}$ at $25 \mu \mathrm{M}$ concentration at $\mathrm{pH} 10(4.05 \pm 0.9 \mathrm{~nm}), \mathrm{pH} 7(3.1 \pm 0.52$ $\mathrm{nm}), \mathrm{pH} 3(4.7 \pm 1.5 \mathrm{~nm})$ and $\mathrm{pH} 1(6.8 \pm 1.8 \mathrm{~nm})$.

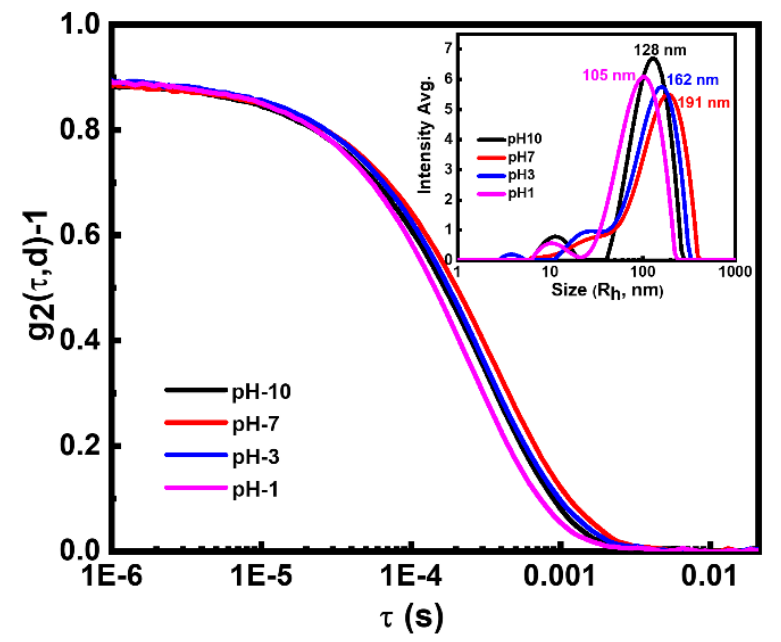

Figure S1b: Dynamic Light Scattering (DLS) plot of decay for autocorrelation function $\left(\mathrm{g}_{2}(\tau, \mathrm{d})\right.$ 1) with respect to $\tau(\mathrm{s})$ and inset showing "intensity" average distribution vs size ( log scale) in solution for PEI $\mathrm{M}_{\mathrm{w}} 750 \mathrm{kDa}$ at $25 \mu \mathrm{M}$ concentration at $\mathrm{pH} 10(128.72 \pm 23.12 \mathrm{~nm})$, pH $7(191.57$ $\pm 9.87 \mathrm{~nm}), \mathrm{pH} 3(162.03 \pm 24.07 \mathrm{~nm})$ and $\mathrm{pH} 1(105.50 \pm 18.92 \mathrm{~nm})$. 

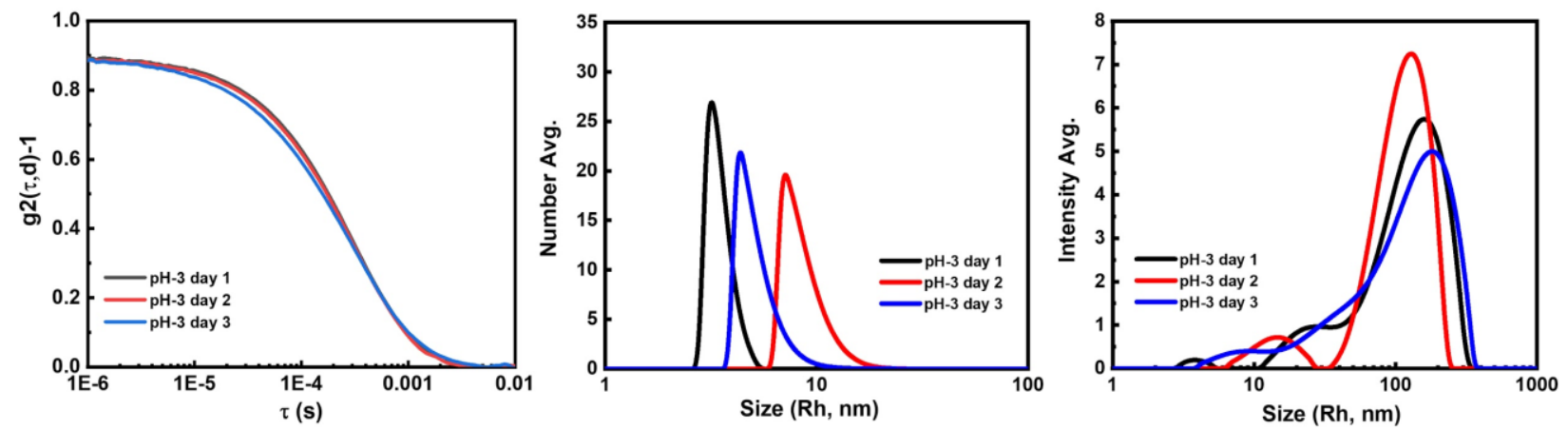

Figure S1c: Time dependent DLS data plot for decay for autocorrelation function $\left(\mathrm{g}_{2}(\tau, \mathrm{d})-1\right)$ with respect to $\tau$ (s) (left plot) shows no difference in the number-average (middle plot) and intensity averaged (right side plot) results for $\mathrm{pH} 3$ samples of $65 \mu \mathrm{M} 750 \mathrm{kDa}$ PEI. This can be due to sedimentation of the larger particles and the fibrils over a period of time.

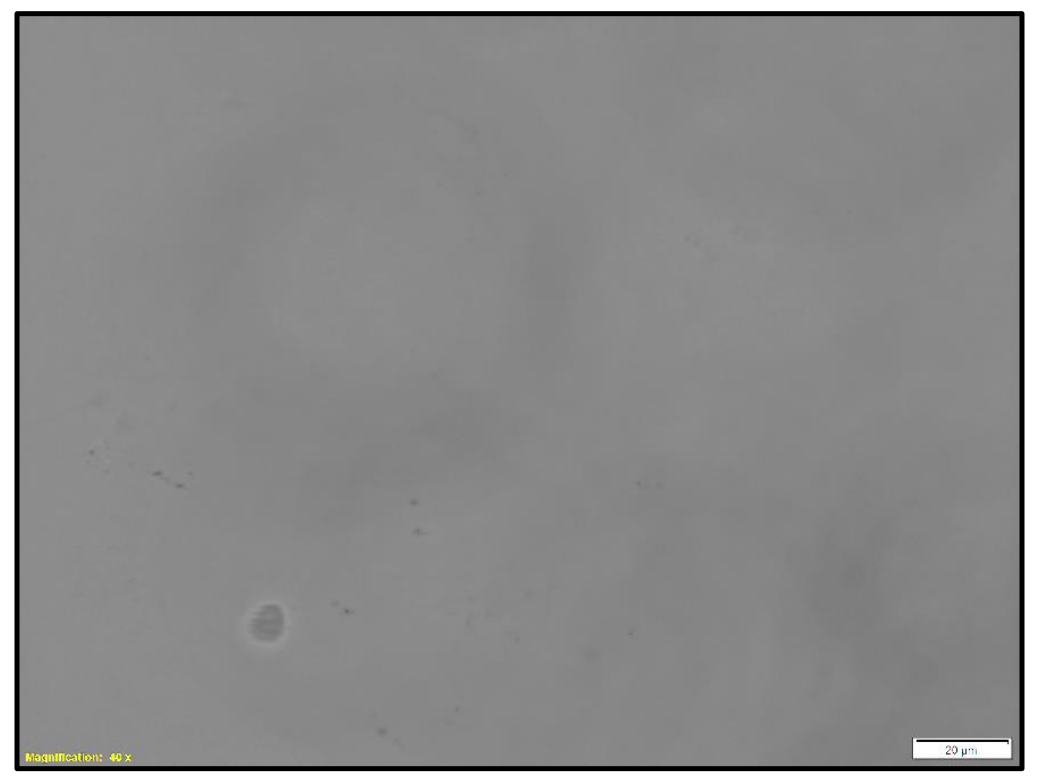

Figure S2: Phase contrast POM of freshly prepared PEI $\mathrm{M}_{\mathrm{w}} 750 \mathrm{kDa}, 65 \mu \mathrm{M} \mathrm{pH} 3$ sample. (Scale bar $20 \mu \mathrm{m}$ ) 

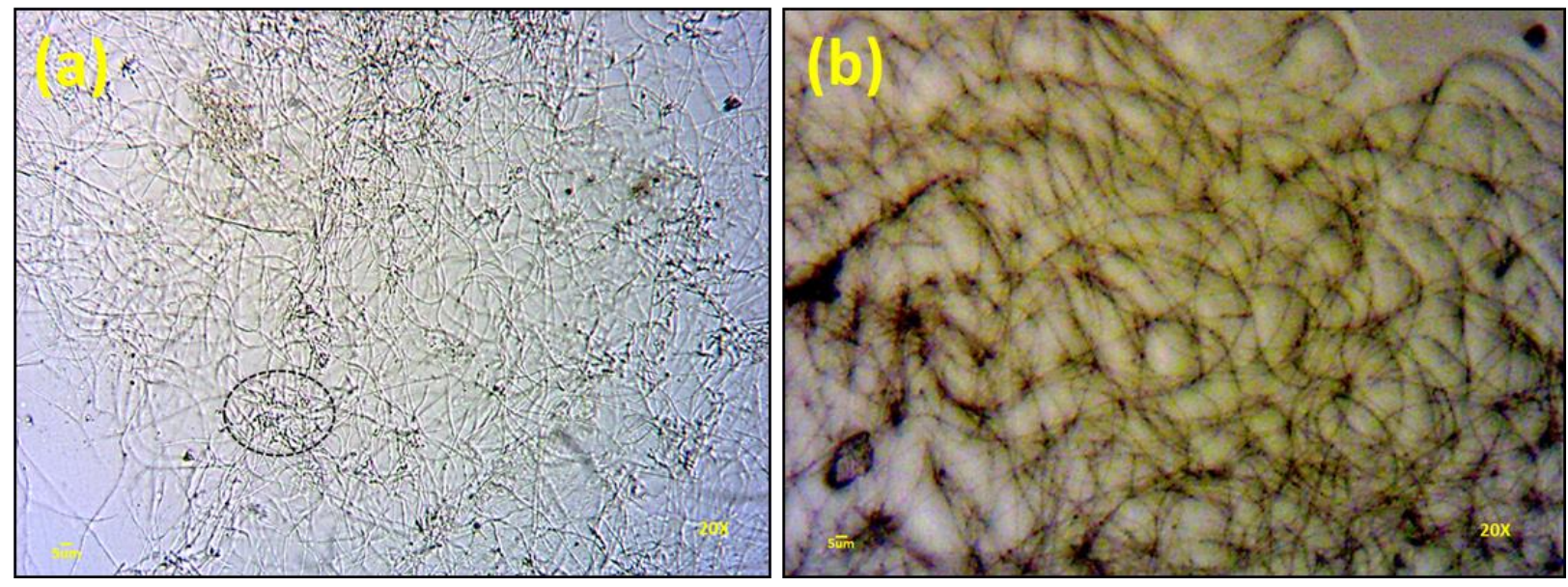

Figure S3a: Optical microscope images to show robustness of PEI $\left(\mathrm{M}_{\mathrm{w}}=750 \mathrm{kDa}, 65 \mu \mathrm{M}\right.$ and $\mathrm{pH}$ 3) fibrils after addition of (a) $2 \mathrm{~N} \mathrm{NaOH}$ (effective $\mathrm{pH} 13.6$ after addition), highlighted area with black outline shows formation of $\mathrm{NaOH}$ crystals while the network of fibrils remains essentially unperturbed (b) excess of $4 \mathrm{~N} \mathrm{HCl}$ (effective $\mathrm{pH} 1.15$ after addition) fibrils remain intact. Images taken at $20 \mathrm{x}$ magnification with a scale bar of $5 \mu \mathrm{m}$.
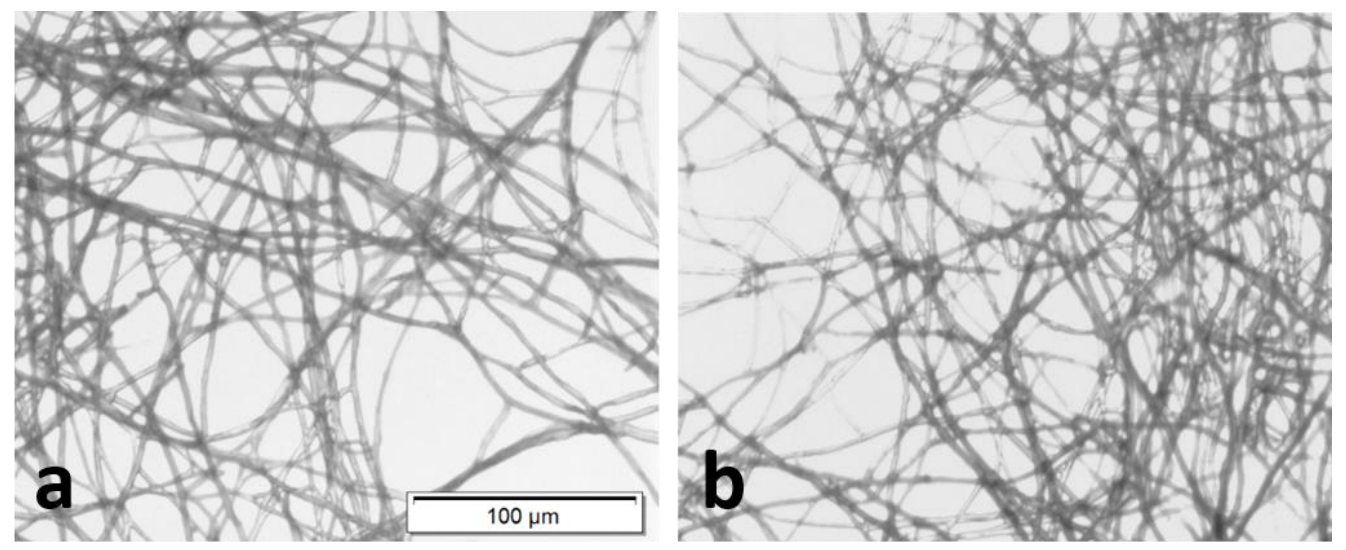

Figure S3b: The irreversibility or no dissolution of fibrils in 90: 10 Ethanol: $\mathrm{H}_{2} \mathrm{O}$ water system. (a) Bright field optical micrographs of the sample immediately after adding the fibrillar network to the 90: 10 solvent and (b) after 24 hrs shows the robustness of the structure. Similar results were obtained for 50: 50 system as well as the $\mathrm{MeOH}: \mathrm{H}_{2} \mathrm{O}$ system, however, they have not been included for the sake of brevity. 

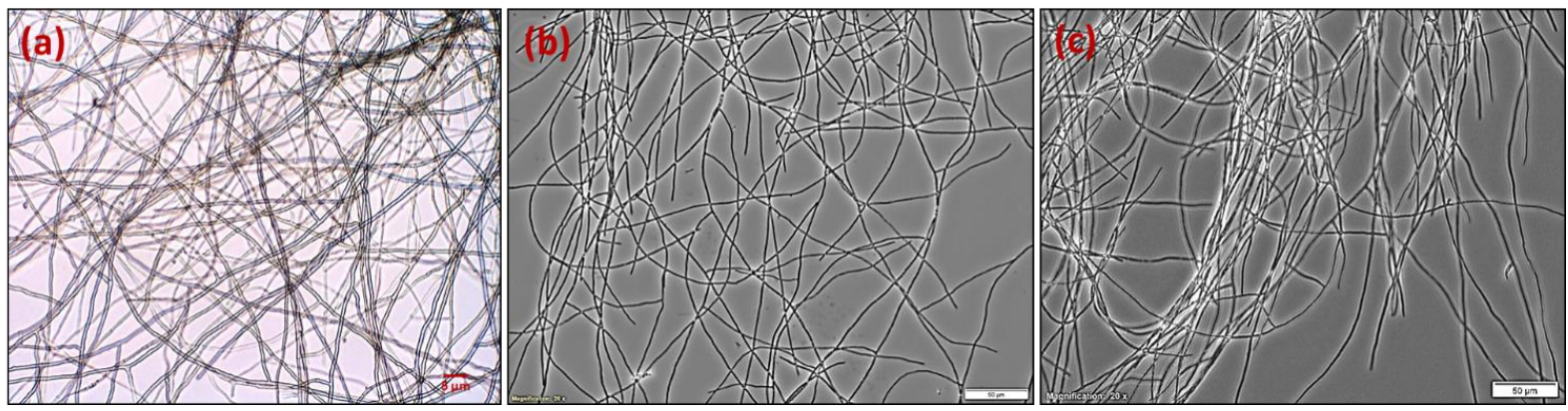

Figure S4: POM images for PEI $\mathrm{M}_{\mathrm{w}} 750 \mathrm{kDa}, 65 \mu \mathrm{M}$ pH 3 to understand effect of different counter ions on PEI and self-assembly.(a) with $6 \mathrm{~N} \mathrm{HCl}$ (obtained at magnification $20 \mathrm{x}$ with scale bar $5 \mu \mathrm{m}$ ) having average thickness $1.55 \mu \mathrm{m}$ (b) with $6 \mathrm{~N} \mathrm{HNO}_{3}$ (obtained under phase contrast with magnification $20 \mathrm{x}$ and scale bar $50 \mu \mathrm{m}$ ) having average thickness $1.34 \mu \mathrm{m}(\mathrm{c})$ with $6 \mathrm{~N} \mathrm{H}_{3} \mathrm{PO}_{4}$ (obtained under phase contrast with magnification $20 \mathrm{x}$ and scale bar $50 \mu \mathrm{m}$ ) having average thickness $1.64 \mu \mathrm{m}$.
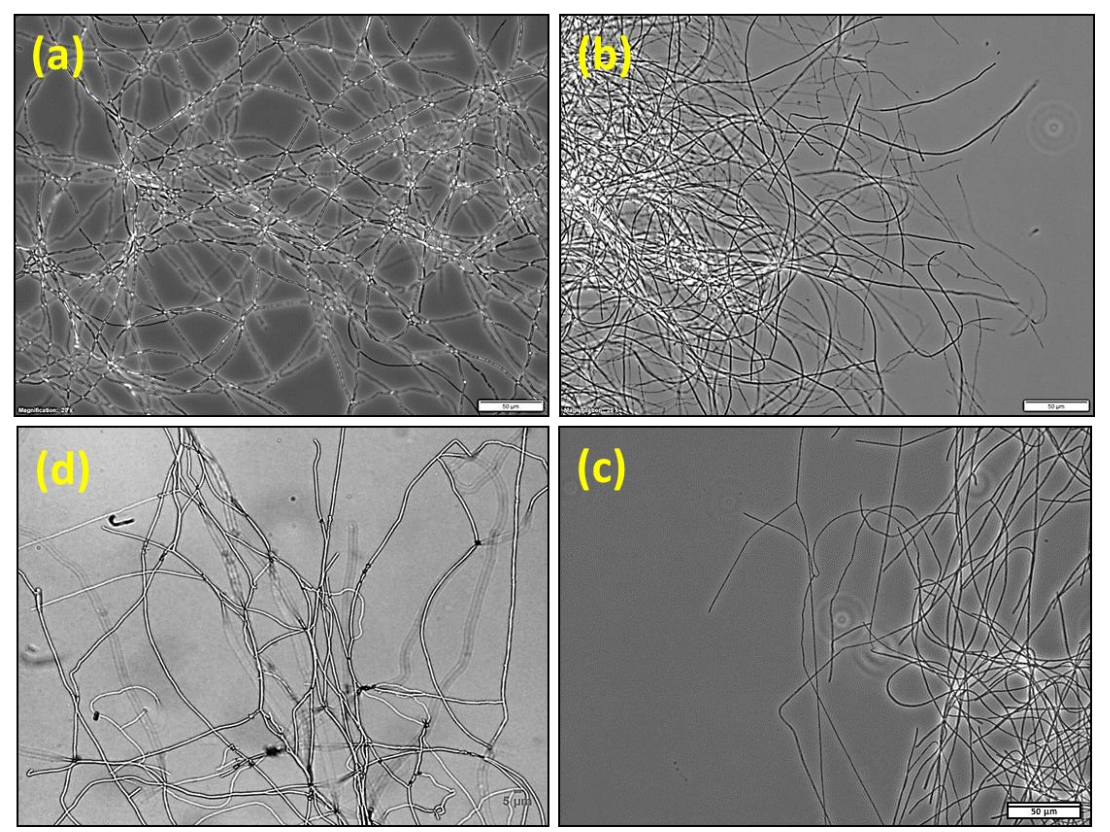

Figure S5: Optical Microscope images to show self-assembly of fibrils and their dependence of molecular weight and linear or branching (images a, b, c obtained under phase contrast mode at $20 \mathrm{x}$ magnification, scale bar $50 \mu \mathrm{m}$ ), (image d obtained under phase contrast at $20 \mathrm{x}$ magnification, scale bar $5 \mu \mathrm{m}$ ) (a)750 kDa branched PEI at $25 \mu \mathrm{M} \mathrm{pH}$ 3, average thickness $2.10 \pm$ $0.40 \mu \mathrm{m}$ (b) $25 \mathrm{kDa}$ branched PEI at $25 \mu \mathrm{M} \mathrm{pH} 3$, average thickness $1.27 \pm 0.31 \mu \mathrm{m}$ (c) $4 \mathrm{kDa}$ linear PEI.HCl at $25 \mu \mathrm{M}$ pH 3, average thickness $1.19 \pm 0.56 \mu \mathrm{m}$ (d) 800 Da branched PEI at 25 $\mu \mathrm{M}$ pH 3, average thickness $1.69 \pm 0.16 \mu \mathrm{m}$. 

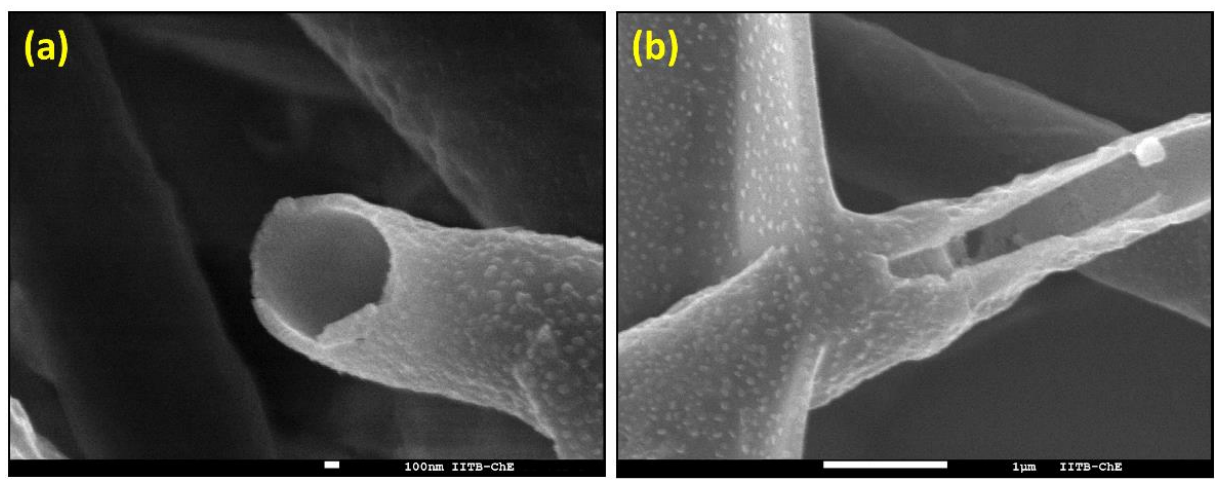

Figure S6: Cryo-SEM (freeze fracture) images for PEI $\mathrm{M}_{\mathrm{w}} 750 \mathrm{kDa}, 65 \mu \mathrm{M}$ at pH 3 after 72 hours. (a) The micrographs show hollow tubular structure (with wall thickness $\approx 100-200 \mathrm{~nm}$ ) of PEI fibrillar network. (b) Polymer filled branched junction which becomes hollow as the fibril network elongates. Scale bar (a) $100 \mathrm{~nm}$, (b) $1 \mu \mathrm{m}$.

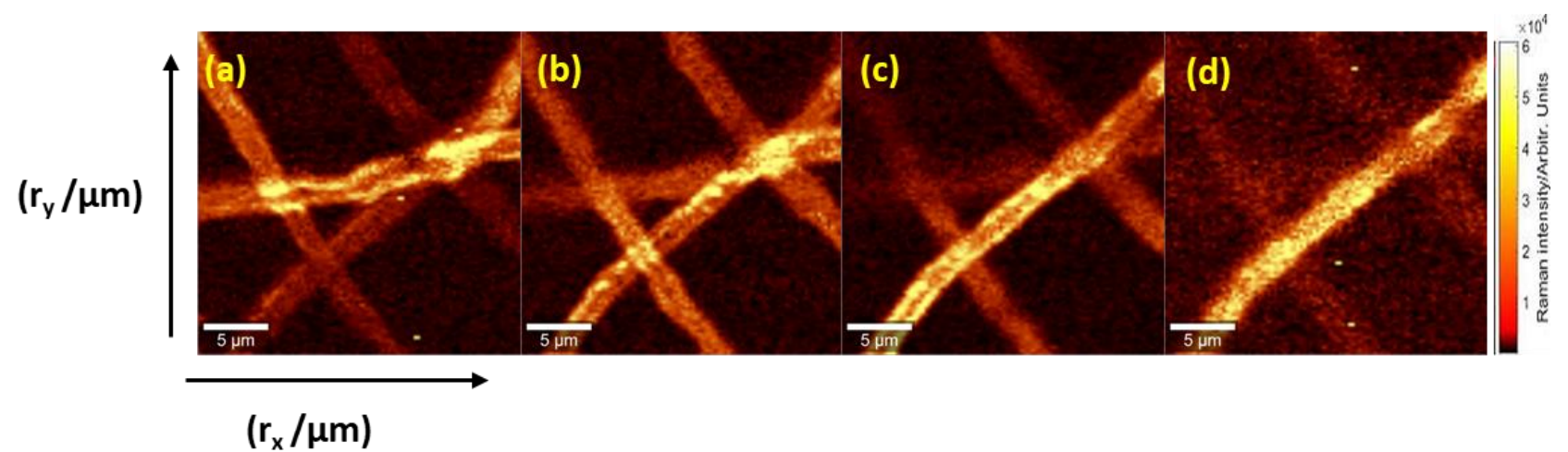

Figure S7: Depth profiles of fibrillar network obtained using Raman confocal Microscopy images for PEI $\mathrm{M}_{\mathrm{w}} 750 \mathrm{kDa}, 65 \mu \mathrm{M}$ and $\mathrm{pH} 3$ samples. Peak intensity was observed to be much lower in the center of the tubular fibrils compared to the edges, correlating with the hollow tubular structures found in cryo-SEM analysis. Scale bar $5 \mu \mathrm{m}$. 


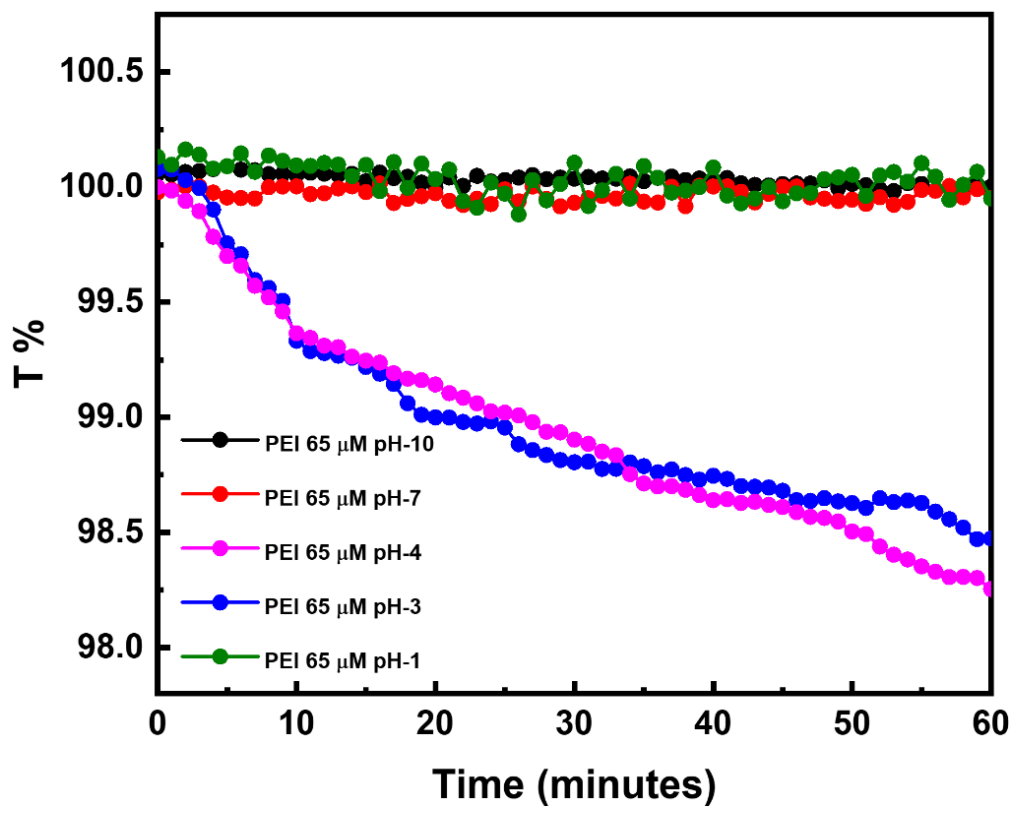

Figure S8: \% Transmission of freshly prepared samples which indicated a systematic decrease in \% Transmittance in $\mathrm{pH} 3$ and $\mathrm{pH} 4$. 